\title{
Desain Pintu Air Berbantu Komputer untuk Saluran Irigasi Tersier di Daerah Irigasi Cikarawang Bogor
}

\author{
(Computer-Aided Design Water Gate for Tertiary Irrigation Channels in
}

Bogor-Cikarawang Irigation Area)

\begin{abstract}
Eka Sulaecha $^{1^{*}}$ dan Budi Indra Setiawan ${ }^{1}$
${ }^{1}$ Departemen Teknik Sipil dan Lingkungan, Fakultas Teknologi Pertanian, Institut Pertanian Bogor. Jl. Raya Dramaga, Kampus IPB Dramaga, PO BOX 220, Bogor, Jawa Barat Indonesia

*Penulis Korespondensi: esulaecha@gmail.com
\end{abstract}

Diterima: 28 Juni 2020

Disetujui: 20 September 2020

\begin{abstract}
Irrigation water gate was one of the supporting components of agricultural activities, especially the management of rice fields, because it was utilized in the management of water flow. The implementation of water gate has a complex and interdependent set of tasks. So that was the problem which can made undesired effects. So that, the planning can be shorted by computer design. Besides, the changes in a design could be overcome quickly and precisely. The purpose of this research is to the effective rainfall, evapotranspiration, discharge of irrigation water needs in the Cikarawang irrigation area, produce a design of computer-aided water gate, and know RAB for the construction of the water gate. The study was conducted from April to July 2020. The place to do the research was Cikarawang Village, Bogor Regency, West Java. The results of the study were the design of water gate by using data plotting with computeraided script files (SCR). The effective rainfall of $1806.3 \mathrm{~mm}$, the highest evapotranspiration of $5.5 \mathrm{~mm} /$ day and the lowest evapotranspiration of plants at $4 \mathrm{~mm} /$ day, the highest irrigation water demand was 2.18 $l t / d t / h a$, The dimensions of $0.5 \times 0.75 \times 0.012 \mathrm{~m}$, and water gate opening $0.27 \mathrm{~m}$. These water gate openings were used when the plant's water requirements are highest. The cost of making water gate made from fiberglass is Rp. 838.000,-while for steel costs Rp. 3.500.000,-.
\end{abstract}

Keywords : Irrigation water needs, SCR, water gate

\section{PENDAHULUAN}

Indonesia merupakan negara yang memiliki curah hujan tinggi. Hal ini sebenarnya merupakan keuntungan dikarenakan jarang terjadi kekeringan di wilayah Indonesia. Tentunya air sangat bermanfaat bagi kehidupan. Sebagai bahan konsumsi ataupun pengairan pada wilayah pertanian. Akan tetapi Indonesia menjadi sangat rentan sekali dengan bencana banjir. Fenomena banjir memang tidak dapat dihindari, namun untuk mengurangi dampak dari banjir dapat dibangun bendungan atau waduk yang dilengkapi pintu air (Apriyanto 2015). Pintu air sudah ada sejak jaman dahulu, dimana jaman dahulu pintu air sangaatlah sederhana. Pintu air sangatlah bermanfaat dan tidak dapat dibayangkan kalau jaman modern ini tidak diikuti dengan perkembangan dari penggunaan pintu air dan pembuatan pintu air.

Pintu air irigasi merupakan salah satu komponen penunjang kegiatan pertanian khususnya pengelolaan sawah, karena dimanfaatkan dalam manajemen pengaturan aliran air. Pengaturan aliran air untuk memenuhi kebutuhan suatu lahan sangat diperlukan dalam perencanaan seberapa banyak air yang akan dialirkan. Untuk mengatur air yang akan disesuaikan dengan kebutuhan, 
JSIL | Sulaecha dan Setiawan : Desain Pintu Air Berbantu Kamputer untuk Saluran Irigasi Tersier di Daerah Irigasi

maka dari itu diperlukan pintu air untuk mengatur air tersebut. Pintu air dikelola oleh para petani sesuai waktu yang disepakati yaitu pagi dan sore. Penyaluran air tergantung pada debit air di saluran utama. Ketika debit air banyak, maka waktu membuka setiap pintu saluran dapat lebih lama. Sedangkan ketika debit air menurun, maka pengaturan buka-tutup pintu air juga disesuaikan agar semua lahan sawah mendapatkan air (Folkes et al 2017).

Pelaksanaan pekerjaan pintu air memiliki rangkaian pekerjaan yang rumit dan saling bergantung satu sama lain. Semakin besar suatu proyek, maka akan semakin kompleks mekanismenya, sehingga semakin banyak masalah yang dihadapi. Mulai dari perencanaan sampai pada pelaksanaan bagaimana penjadwalan, pengendalian dan kontrol proyek dengan baik. Sehingga dalam masalah tersebut menimbulkan dampak yang tidak diinginkan. Untuk pengendalian dampak yang akan ditimbulkan tersebut yaitu dengan pengendalian waktu dalam perencaanaan pembuatan pintu air dengan menggunakan bantuan komputer yang waktu demi waktu mengalami kemajuan yang sangat pesat. Dengan bantuan komputer waktu perencanaan dapat dipersingkat. Selain itu terjadinya perubahan pada suatu perancangan bisa diatasi dengan cepat dan tepat, dengan mengganti beberapa faktor penting didalamnya.

Tujuan dilaksanakannya penelitian ini yaitu untuk mengetahui curah hujan efektif, evapotranspirasi, debit kebutuhan air irigasi di Daerah Irigasi Cikarawang, menghasilkan rancangan desain pintu air berbantu computer, serta mengetahui RAB untuk pembangunan pintu air.

\section{METODOLOGI}

Penelitian dilakukan dari bulan April hingga Juli 2020. Tempat dilakukannya penelitian adalah Desa Cikarawang, Kabupaten Bogor, Jawa Barat. Lokasi pelaksanaan disajikan pada Gambar 1.

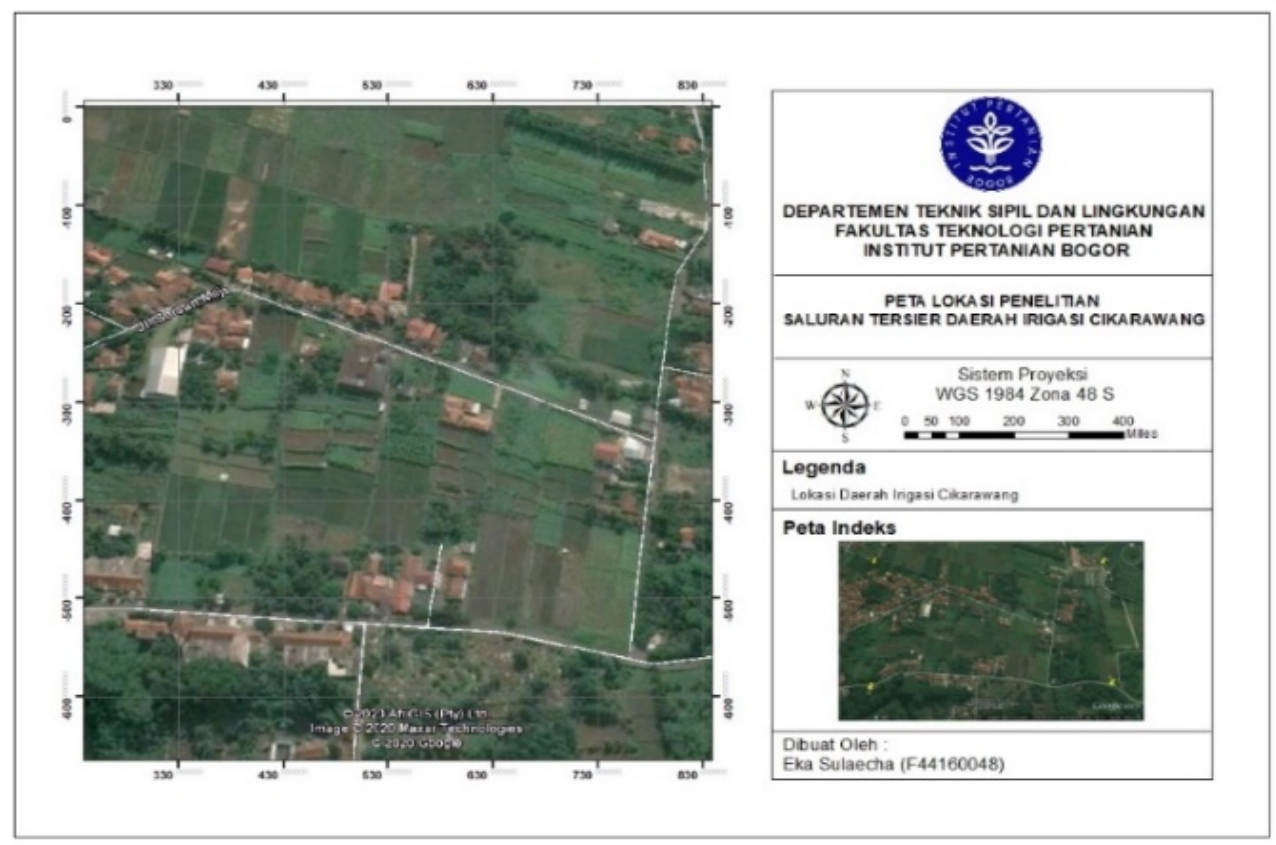

Gambar 1 Lokasi Penelitian 
Alat yang digunakan dalam penelitian ini antara lain komputer yang dilengkapi perangkat lunak Microsoft Office, AutoCAD, serta alat tulis. Bahan yang digunakan pada penelitian adalah luas petak tersier dan data curah hujan yang diperoleh dari BMKG Dramaga, Bogor. Tahapan penelitian digambarkan melalui bagan alir yang disajikan pada Gambar 2.

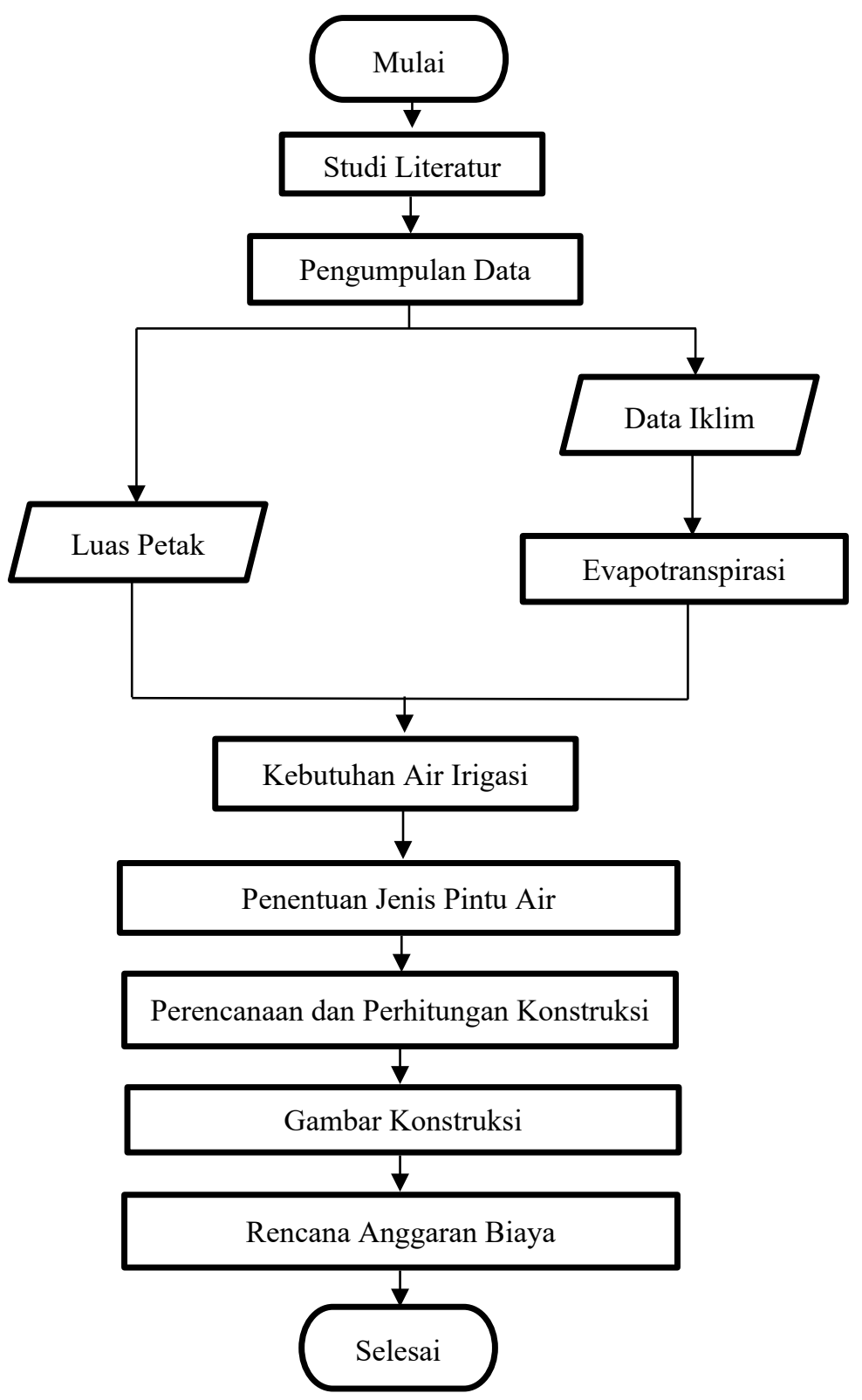

Gambar 2 Diagram Alir Penelitian 
JSIL | Sulaecha dan Setiawan : Desain Pintu Air Berbantu Kamputer untuk Saluran Irigasi Tersier di Daerah Irigasi

\section{Kebutuhan Air Irigasi}

Kebutuhan air untuk penyiapan lahan umumnya menentukan kebutuhan maksimum air irigasi pada suatu proyek irigasi. Metode tersebut didasarkan pada laju air konstan dalam It/dt selama periode penyiapan lahan dan menghasilkan rumus (1).

$\mathrm{IR}=\mathrm{Me}^{\mathrm{k}} /\left(\mathrm{e}^{\mathrm{k}}-1\right)$

Keterangan:

IR = Kebutuhan air penyiapan lahan (mm/hari)

$\mathrm{M}=$ Kebutuhan air untuk mengganti kehilangan air akibat evaporasi dan perkolasi di sawah yang sudah dijenuhkan $(\mathrm{M}=\mathrm{Eo}+\mathrm{P}$ (mm/hari))

Eo = Evaporasi air terbuka yang diambil 1,1 Eto selama penyiapan lahan ( $\mathrm{mm} / \mathrm{hari})$

$\mathrm{P}=$ Perkolasi $(\mathrm{mm} /$ hari $)$

$\mathrm{k} \quad=\mathrm{Mx}(\mathrm{T} / \mathrm{S})$

$\mathrm{T}=$ Jangka waktu penyiapan lahan (30 hari)

$\mathrm{S}=$ Kebutuhan air penjenuhan (250 mm)

e $\quad=$ Bilangan Alam / Naperian Number $(2,71828)$

Kebutuhan air untuk tanaman di lahan diartikan sebagai penggunaan konsumtif dengan memasukkan faktor koefisien tanaman $\left(\mathrm{K}_{\mathrm{c}}\right)$. Jumlah air yang akan dipakai oleh tanaman untuk proses fotosistensis disebut penggunaan konsumtif $\mathrm{ET}_{\mathrm{c}}$ dan dihitung dengan persamaan (2). Evapotranspirasi dapat dihitung dengan persamaan (3).

$\mathrm{ET}_{\mathrm{c}}=\mathrm{K}_{\mathrm{c}} . \mathrm{ET}_{0}$

$\mathrm{ET}_{\mathrm{o}}=\mathrm{K}_{\mathrm{p}} \cdot E_{\text {pan }}$
Keterangan:

$\mathrm{ET}_{\mathrm{o}}=$ Evapotranspirasi tanaman acuan (mm/hari)

$\mathrm{ET}_{\mathrm{c}}=$ Evapotranspirasi tanaman ( $\mathrm{mm} / \mathrm{hari})$

$E_{p a n}=$ Harga-harga panci evaporasi dikonversi ke dalam angka-angka $\mathrm{ET}_{\mathrm{o}}$

$\mathrm{K}_{\mathrm{p}}=$ Faktor pan $(0,65$ dan 0,85 bergantung kepada kecepatan angin, kelembapan relatif serta elevasi)

$\mathrm{K}_{\mathrm{c}} \quad=$ Koefisien tanaman

Analisis curah hujan dilakukan dengan maksud untuk menentukan curah hujan efektif untuk menghitung kebutuhan irigasi.

$R_{e} \quad=0,7 \times \frac{1}{15} R($ Setengah bulan $)$

Keterangan:

$R_{e} \quad=$ Curah hujan efektif ( $\left.\mathrm{mm} / \mathrm{hari}\right)$ $R$ (setengah bulan) $5=$ Curah hujan minimum tengah bulanan dengan periode ulang 5 tahun ( $\mathrm{mm}$ )

Banyaknya kebutuhan irigasi disawah dapat dirumuskan seperti pada persamaan (5) dan kebutuhan air di sumbernya dapat diperkirakan dengan persamaan (6).

$\mathrm{NFR}=\mathrm{Etc}+\mathrm{P}+\mathrm{WLR}-\mathrm{Re}$

Keterangan:

$\mathrm{NFR}=$ netto field water requirement, kebutuhan bersih air di sawah (mm/hari)

Etc $=$ Evaporasi tanaman $(\mathrm{mm} /$ hari $)$

$\mathrm{P} \quad=$ Perkolasi $(\mathrm{mm} /$ hari $)$

$\mathrm{Re} \quad=$ Curah hujan efektif (mm/hari)

WLR = Kedua penggantian lapis air ( $\mathrm{mm} /$ hari) 
IR $=\frac{N F R}{E f}$

Keterangan:

$\begin{aligned} \text { IR } \quad & \text { Kebutuhan air irigasi } \\ & (\mathrm{mm} / \text { hari }) \\ \text { Ef } \quad & \text { Efisiensi yang terdiri dari } \\ & \text { efisiensi di saluran dan } \\ & \text { bangunan tersier, sekunder dan } \\ & \text { primer. }\end{aligned}$

\section{Pintu Air}

Debit yang melewati pintu sorong untuk saluran segi empat dapat dihitung dengan menggunakan persamaan (7). Swamee (1992) mengembangkan persamaan yang dapat digunakan untuk menentukan kondisi aliran yang terjadi pada pintu sorong yang disajikan pada persamaan (8) dan (9). Cd untuk aliran bebas digunakan persamaan (10) dan Cd untuk aliran terendam digunakan persamaan (11).

$\mathrm{Q} \quad \mathrm{C}_{\mathrm{d}} \cdot \mathrm{b} \cdot \mathrm{a} \cdot \sqrt{2 g \mathrm{ho}}$

Aliran bebas

$\mathrm{h}_{\mathrm{o}} \geq 0,81 \mathrm{~h}_{2}\left(\frac{h 2}{a}\right)^{0,72}$

$\mathrm{C}_{\mathrm{d}}=0,611\left(\frac{h o-a}{h o+15 a}\right)^{0,072}$

Aliran terendam

$\mathrm{h}_{2}<\mathrm{h}_{\mathrm{o}}<0,81 \mathrm{~h}_{2}\left(\frac{h 2}{a}\right)^{0,72}$

$\mathrm{C}_{\mathrm{d}}=0,611\left(\frac{h o-a}{h 0+15 a}\right)^{0,072}$

$\left(\mathrm{h}_{\mathrm{o}}-\mathrm{h}_{2}\right)^{0,7}\left\{0,32\left[0,81 \mathrm{~h}_{2}\left(\frac{h 2}{a}\right)^{0,72}-\mathrm{h}_{\mathrm{o}}{ }^{0,7}\right]\right.$

$\left.+\left(\mathrm{h}_{\mathrm{o}}-\mathrm{h}_{2}\right)^{0,7}\right\}^{-1}$

Keterangan;

Q $=$ Debit melewati pintu sorong $\left(\mathrm{m}^{3} / \mathrm{det}\right)$

$\mathrm{C}_{\mathrm{d}} \quad=$ Koefisien debit

$\mathrm{b}=$ Lebar saluran $(\mathrm{m})$ a $\quad=$ Bukaan pintu (m)

$\mathrm{g} \quad=$ Percepatann gravitasi

$\mathrm{h}_{\mathrm{o}} \quad=$ Tinggi muka air di hulu pintu (m)

$\mathrm{h}_{2} \quad=$ Tinggi muka air di hilir pintu (m)

\section{Rencana Anggaran Biaya}

Rencana anggaran biaya ini dilakukan untuk mengetahui besarnya biaya yang akan dikeluarkan jika membangun pintu air.

\section{HASIL DAN PEMBAHASAN}

\section{Gambaran Umum}

Lokasi penelitian ini berada di Desa Cikarawang - Dramaga, Kabupaten Bogor. Desa Cikarawang merupakan salah satu desa yang berada di Kecamatan Dramaga, Kabupaten Bogor, Provinsi Jawa Barat. Wilayah Desa Cikarawang berbatasan dengan Sungai Cisadane pada bagian utara, Sungai Ciapus pada bagian selatan, Sungai Cianduan pada bagian barat, dan kelurahan Situ Gede pada bagian timur. Sebagian besar penduduk di Desa Cikarawang bekerja sebagai petani. Luas wilayah desa adalah 226,56 ha yang terdiri dari lahan sawah dan ladang seluas 194,572 ha, lahan pemukiman atau perumahan seluas 37,854 ha, lahan empang seluas 2,15 ha, lahan perkuburan seluas 0,6 ha, dan sisanya digunakan untuk jalan. Desa Cikarawang juga memiliki danau (situ), yang diberi nama Situ Burung. Danau (situ) seluas kurang lebih 2,5 ha tersebut berfungsi sebagai sumber air untuk irigasi persawahan, sebagai reservoir air yang mampu mencegah banjir di musim hujan dan mencegah kekurangan air di musim kemarau. 


\section{Kebutuhan Air Irigasi}

Daerah Irigasi yang terletak di Desa Cikarawang - Dramaga, Kabupaten Bogor ini memiliki stasiun hujan yaitu BMKG Dramaga Bogor.
Curah hujan rata-rata dihitung dengan metode aljabar. Curah hujan diambil dari 10 tahun 2010 - 2019. Dari stasiun hujan ini diambil curah hujan disajikan pada Tabel 1.

Tabel 1 Rekapitulasi Urutan Data Curah Hujan dari yang Terbesar sampai yang Terkecil dan Ranking yang Dipilih

\begin{tabular}{|c|c|c|c|c|c|c|c|c|c|c|c|}
\hline \multirow{2}{*}{ Tahun } & \multicolumn{11}{|c|}{ Curah Hujan peringkat Ke } \\
\hline & & 1 & 2 & 3 & 4 & 5 & 6 & 7 & 8 & 9 & 10 \\
\hline \multirow{2}{*}{ JAN } & 1 & 332 & 273.5 & 259.9 & 205.3 & 163 & 158.7 & 102.8 & 94.6 & 80.4 & 61.3 \\
\hline & 2 & 428.5 & 202.4 & 185.2 & 177.8 & 127.2 & 103.2 & 93.3 & 66.4 & 50 & 39.7 \\
\hline \multirow{2}{*}{ FEB } & 1 & 340.2 & 309 & 283.8 & 269.6 & 233.4 & 193 & 192.2 & 160.9 & 65.7 & 41.8 \\
\hline & 2 & 334.3 & 314.2 & 308.4 & 211.5 & 176.5 & 151.7 & 105.9 & 66 & 62.8 & 34.7 \\
\hline \multirow{2}{*}{ MAR } & 1 & 328.5 & 220.9 & 170.5 & 127.7 & 117.3 & 105.1 & 98.6 & 79.8 & 72.7 & 61.6 \\
\hline & 2 & 205.1 & 193.6 & 165.1 & 164.1 & 162.1 & 121.5 & 78.4 & 63 & 60.3 & 37.4 \\
\hline \multirow{2}{*}{ APR } & 1 & 212.2 & 208.4 & 195.3 & 188 & 162.9 & 144.6 & 131.3 & 116.9 & 100.2 & 31.4 \\
\hline & 2 & 475.5 & 349.8 & 298.7 & 226.6 & 183.7 & 167.8 & 133.8 & 99.1 & 62.6 & 11.5 \\
\hline \multirow{2}{*}{ MEI } & 1 & 277.9 & 186.2 & 164.2 & 163.8 & 157.6 & 140.7 & 111.5 & 110.7 & 86 & 62.8 \\
\hline & 2 & 275.7 & 221.3 & 189 & 173.3 & 132.2 & 125.9 & 121.4 & 89.6 & 84.6 & 83.3 \\
\hline \multirow{2}{*}{ JUN } & 1 & 257.4 & 208.6 & 129 & 89.8 & 86 & 84.1 & 71.7 & 71.3 & 51.2 & 23.2 \\
\hline & 2 & 270.6 & 231.7 & 188.9 & 115.7 & 66 & 51.5 & 39.1 & 33.5 & 9.8 & 0.4 \\
\hline \multirow{2}{*}{ JUL } & 1 & 225.2 & 212.6 & 143.6 & 118.5 & 117.2 & 89.8 & 89.1 & 52.7 & 37.9 & 0.2 \\
\hline & 2 & 284.7 & 181.3 & 148.9 & 136.4 & 135 & 112.2 & 34.8 & 1.4 & 0.4 & 0.1 \\
\hline \multirow{2}{*}{ AGT } & 1 & 229.8 & 145.9 & 135.7 & 121.1 & 94.7 & 75.4 & 60.4 & 21.3 & 0 & 0 \\
\hline & 2 & 392.5 & 356.5 & 170.3 & 85.8 & 81.6 & 52.4 & 43.5 & 3.9 & 1 & 0 \\
\hline \multirow{2}{*}{ SEP } & 1 & 446.3 & 301.5 & 130.1 & 84.6 & 48.9 & 32.8 & 31.6 & 6.4 & 6.4 & 3.2 \\
\hline & 2 & 185.9 & 154.7 & 136.7 & 118.8 & 108.5 & 76.6 & 74.3 & 42.4 & 15.4 & 0 \\
\hline \multirow{2}{*}{$\mathrm{OKT}$} & 1 & 312.2 & 228 & 204 & 188.6 & 174.2 & 119.7 & 98.8 & 41.5 & 41.1 & 34.3 \\
\hline & 2 & 370 & 273.9 & 227.3 & 207.9 & 187.1 & 177.9 & 157.2 & 146 & 127.9 & 63.6 \\
\hline \multirow{2}{*}{ NOP } & 1 & 430.8 & 430.4 & 282.5 & 193.5 & 164.9 & 146 & 143.4 & 110.4 & 88.4 & 59.4 \\
\hline & 2 & 407.9 & 266.4 & 264.2 & 242.8 & 224.8 & 221.8 & 219.7 & 179.8 & 118.4 & 40.9 \\
\hline \multirow{2}{*}{ DES } & 1 & 389 & 378.1 & 283.6 & 260.5 & 181.9 & 175.3 & 114 & 91.5 & 66.9 & 12.4 \\
\hline & 2 & 1744.7 & 190.7 & 187.6 & 176.9 & 169.3 & 124.1 & 63.3 & 57.2 & 49.7 & 41.6 \\
\hline
\end{tabular}

Pada Tabel 2 disajikan hasil dari curah hujan efektif yang didapatkan dari urutan data curah hujan dari yang terbesar sampai yang terkecil dan berdasarkan urutan tersebut dibuatkan rangking yang nantinya akan dipilih untuk curah hujan efektif. Curah hujan efektif didapatkan dari rangking ke 8 (80 $\%$ yang tertera pada Tabel 1. Berdasarkan nilai yang disajikan pada Tabel 2 mendapatkan akumulasi nilai curah hujan efektif sebesar 1806,3 mm. Hasil dari curah hujan efektif untuk padi dan palawija terdapat pada Tabel 3 .
Curah hujan efektif irigasi tanaman padi diambil $70 \%$ sedangkan untuk palawija diambil $50 \%$ dari curah hujan rata-rata tengah bulanan dengan kemungkinan tak terpenuhi 20\% (curah hujan R80). Pada curah hujan efektif untuk padi terbesar didapatkan dibulan November yaitu periode 1 sebesar $5.2 \mathrm{~mm} /$ hari dan 8.4 $\mathrm{mm} /$ hari atau sebesar $13.5 \mathrm{~mm} /$ bulan. Sedangkan untuk palawija didapatkan curah hujan efektif tersebar pada bulan November yaitu periode 1 sebesar 3.4 dan periode 2 sebesar 3.4 atau sebesar $6.8 \mathrm{~mm} /$ bulan. 
JSIL JURNAL TEKNIK SIPILDAN LINGKUNGAN| EISSN:2549-1407

Tabel 2 Hasil Curah Hujan Efektif

\begin{tabular}{|c|c|c|c|c|c|}
\hline Bulan & Periode & R80 & Bulan & Periode & R80 \\
\hline \multirow{2}{*}{ JAN } & 1 & 94.6 & \multirow{2}{*}{ JUL } & 1 & 52.7 \\
\hline & 2 & 66.4 & & 2 & 1.4 \\
\hline \multirow{2}{*}{ FEB } & 1 & 160.9 & \multirow{2}{*}{ AGT } & 1 & 21.3 \\
\hline & 2 & 66 & & 2 & 3.9 \\
\hline \multirow{2}{*}{ MAR } & 1 & 79.8 & \multirow{2}{*}{ SEP } & 1 & 6.4 \\
\hline & 2 & 63 & & 2 & 42.4 \\
\hline \multirow{2}{*}{ APR } & 1 & 116.9 & \multirow{2}{*}{ OKT } & 1 & 41.5 \\
\hline & 2 & 99.1 & & 2 & 146 \\
\hline \multirow{2}{*}{ MEI } & 1 & 110.7 & \multirow{2}{*}{ NOP } & 1 & 110.4 \\
\hline & 2 & 89.6 & & 2 & 179.8 \\
\hline \multirow{2}{*}{ JUN } & 1 & 71.3 & \multirow{2}{*}{ DES } & 1 & 91.5 \\
\hline & 2 & 33.5 & & 2 & 57.2 \\
\hline
\end{tabular}

Tabel 3 Hasil Curah Hujan Efektif untuk Padi dan Palawija

\begin{tabular}{cccccccc}
\hline & & \multicolumn{6}{c}{ Re Padi } \\
\cline { 4 - 8 } Bulan & Periode & R80 & \multicolumn{3}{c}{ Re Palawija } \\
& & & $70 \%$ R 80 & mm/hari & $50 \%$ R 80 & $\mathrm{~mm} /$ bulan & mm/hari \\
\hline \multirow{2}{*}{ JAN } & 1 & 94.6 & 66.2 & 4.4 & 47.3 & 56.4 & 1.9 \\
& 2 & 66.4 & 46.5 & 3.1 & 33.2 & & 1.9 \\
FEB & 1 & 160.9 & 112.6 & 7.5 & 80.5 & 79.4 & 2.6 \\
& 2 & 66 & 46.2 & 3.1 & 33.0 & & 2.6 \\
MAR & 1 & 79.8 & 55.9 & 3.7 & 39.9 & 50.0 & 1.7 \\
& 2 & 63 & 44.1 & 2.9 & 31.5 & & 1.7 \\
APR & 1 & 116.9 & 81.8 & 5.5 & 58.5 & 75.6 & 2.5 \\
& 2 & 99.1 & 69.4 & 4.6 & 49.6 & & 2.5 \\
MEI & 1 & 110.7 & 77.5 & 5.2 & 55.4 & 70.1 & 2.3 \\
& 2 & 89.6 & 62.7 & 4.2 & 44.8 & & 2.3 \\
JUN & 1 & 71.3 & 49.9 & 3.3 & 35.7 & 36.7 & 1.2 \\
& 2 & 33.5 & 23.5 & 1.6 & 16.8 & & 1.2 \\
JUL & 1 & 52.7 & 36.9 & 2.5 & 26.4 & 18.9 & 0.6 \\
& 2 & 1.4 & 1.0 & 0.1 & 0.7 & & 0.6 \\
AGT & 1 & 21.3 & 14.9 & 1.0 & 10.7 & 8.8 & 0.3 \\
& 2 & 3.9 & 2.7 & 0.2 & 2.0 & & 0.3 \\
SEP & 1 & 6.4 & 4.5 & 0.3 & 3.2 & 17.1 & 0.6 \\
& 2 & 42.4 & 29.7 & 2.0 & 21.2 & & 0.6 \\
OKT & 1 & 41.5 & 29.1 & 1.9 & 20.8 & 65.6 & 2.2 \\
& 2 & 146 & 102.2 & 6.8 & 73.0 & & 2.2 \\
NOP & 1 & 110.4 & 77.3 & 5.2 & 55.2 & 101.6 & 3.4 \\
& 2 & 179.8 & 125.9 & 8.4 & 89.9 & & 3.4 \\
DES & 1 & 91.5 & 64.1 & 4.3 & 45.75 & 52.05 & 1.7 \\
& 2 & 57.2 & 40.04 & 2.67 & 28.60 & & 1.7 \\
\hline
\end{tabular}


JSIL | Sulaecha dan Setiawan : Desain Pintu Air Berbantu Kamputer untuk Saluran Irigasi Tersier di Daerah Irigasi

Cikarawang Bogor

Tabel 4 Hasil Evapotranspirasi Tanaman Acuan

\begin{tabular}{cccc}
\hline Bulan & ETo (mm/hari) & Bulan & ETo (mm/hari) \\
\hline JAN & 4.5 & JUL & 3.9 \\
FEB & 4.9 & AGT & 4.1 \\
MAR & 4.6 & SEP & 4.5 \\
APR & 4.4 & OKT & 5.0 \\
MEI & 3.9 & NOP & 4.8 \\
JUN & 3.7 & DES & 4.7 \\
\hline
\end{tabular}

Hasil dari evapontraspirasi tanaman acuan didapatkan dari evapotranspirasi tanaman yang dijadikan acuan, yakni rerumputan pendek. Berdasarkan Tabel 4 terlihat bahwa nilai $\mathrm{ET}_{\mathrm{o}}$ cenderung fluktuatif, hal ini dikarenakan banyak faktor yang mempengaruhinya. Sehingga nilai $\mathrm{ET}_{\mathrm{o}}$ terbesar ada pada bulan Oktober sebesar $5 \mathrm{~mm} /$ hari. Salah satu faktor yang sangat berpengaruh adalah penyinaran matahari, semakin besar nilai penyinaran matahari maka semakin kecil pula nilai $\mathrm{ET}_{\mathrm{o}}$.

Berdasarkan Tabel 5 hasil dari kebutuhan air tanaman juga memiliki nilai yang fluktuatif. Hal ini dikarenakan nilai evapotranspirasi tanaman mengikuti evapotranspirasi acuan $\left(\mathrm{ET}_{\mathrm{o}}\right)$. Nilai yang didapatkan mengalami penurunan pada setiap musim tanamnya dan akan naik lagi jika akan mengalami penyiapan lahan kembali untuk melakukan penanaman lagi. Pada musim tanam I bulan November-Februari, Musim tanam II bulan (Maret-Juni, dan Musim tanam II bulan Juli-Oktober. Pada musim tanam I nilai evapotranspirasi mengalami penurunan dan akan naik lagi jika akan dilakukan penyiapan lahan kembali atau masa peralihan. Nilai ETc harian maksimum selama periode tanam sebesar 5.5 $\mathrm{mm} /$ hari dan ETc minimum sebesar 4 $\mathrm{mm}$ /hari. Nilai ETc rata-rata selama periode tanam adalah $4,9 \mathrm{~mm}$.

Tabel 5 Hasil Evapotrasnpirasi Tanaman

\begin{tabular}{cccc}
\hline Bulan & ETc $(\mathrm{mm} /$ hari $)$ & Bulan & ETc $(\mathrm{mm} /$ hari $)$ \\
\hline JAN & 4.9 & JUL & 4.3 \\
FEB & 5.5 & AGT & 4.5 \\
MAR & 5.1 & SEP & 4.9 \\
APR & 4.9 & OKT & 5.5 \\
MEI & 4.3 & NOP & 5.3 \\
JUN & 4.0 & DES & 5.2 \\
\hline
\end{tabular}

Jenis tanah pada lokasi penelitian merupakan tanah liat berdebu. Tanah liat berdebu merupakan jenis tanah yang bertekstur halus yang pada umumnya mempunyai kemampuan drainase agak buruk akan tetapi mempunyai daya simpan air yang relatif tinggi, kondisi jenuhnya di daerah perakaran dapat bertahan lama namun aerasinya cukup baik sehingga sesuai untuk lahan sawah.
Pada tanah lempung berat dengan karakteristik pengelolahan yang baik, laju perkolasi dapat mencapai 1-3 $\mathrm{mm}$ /hari (KemenPU 2013). Oleh sebab itu nilai perkolasi yang digunakan yaitu sebesar $2 \mathrm{~mm} /$ hari.

Pola tanam yang dipakai di lokasi tersebut yaitu padi-padi-palawija dengan pola tanam dalam satu tahun. Di lokasi tersebut memiliki pola tanam padi-padi- 
palawija dikarenakan ketersediaan air cukup banyak. Untuk jenis tanaman yang dipakai juga dua jenis tanaman atau lebih dalam satu periode seperti tanaman semusim. Untuk tanaman semusim nya sendiri yaitu padi, jagung, dan ubi kayu.

Pada Tabel 6 disajikan hasil dari kebutuhan air penyiapan lahan. Nilai untuk kebutuhan air penyiapan lahan terbesar yaitu pada bulan Oktober sebesar $16.4 \mathrm{~mm} /$ hari, hal ini sejalan dengan nilai terbesar pada nilai evapotranspirasi yaitu pada bulan Oktober. Jika Nilai evapotranspirasi besar maka kebutuhan air untuk penyiapan lahan juga besar. Nilai evapotranspirasi dengan kebutuhan air penyiapan lahan berbanding lurus.

Tabel 6 Hasil Kebutuhan Air Penyiapan Lahan

\begin{tabular}{|c|c|c|c|c|c|c|c|c|}
\hline \multirow{2}{*}{ Bulan } & ETo & Eo & $\mathrm{P}$ & $\mathrm{M}$ & $\mathrm{T}$ & $\mathrm{S}$ & \multirow{2}{*}{$\mathrm{K}$} & IR \\
\hline & \multicolumn{4}{|c|}{ (mm/hari) } & hari & $\mathrm{mm}$ & & (mm/hari) \\
\hline JAN & 4.5 & 4.9 & 2 & 9.9 & 30 & 300 & 1.0 & 15.7 \\
\hline FEB & 5.0 & 5.5 & 2 & 10.9 & 30 & 300 & 1.1 & 16.4 \\
\hline MAR & 4.6 & 5.1 & 2 & 10.1 & 30 & 300 & 1.0 & 15.9 \\
\hline APR & 4.4 & 4.9 & 2 & 9.8 & 30 & 300 & 1.0 & 15.7 \\
\hline MEI & 3.9 & 4.3 & 2 & 8.7 & 30 & 300 & 0.9 & 15.0 \\
\hline JUN & 3.7 & 4.0 & 2 & 8.1 & 30 & 300 & 0.8 & 14.6 \\
\hline JUL & 3.9 & 4.3 & 2 & 8.6 & 30 & 300 & 0.9 & 14.9 \\
\hline $\mathrm{AGT}$ & 4.1 & 4.5 & 2 & 9.1 & 30 & 300 & 0.9 & 15.2 \\
\hline SEP & 4.5 & 4.9 & 2 & 9.8 & 30 & 300 & 1.0 & 15.7 \\
\hline $\mathrm{OKT}$ & 5.0 & 5.5 & 2 & 10.9 & 30 & 300 & 1.1 & 16.4 \\
\hline NOP & 4.8 & 5.3 & 2 & 10.6 & 30 & 300 & 1.1 & 16.2 \\
\hline DES & 4.7 & 5.2 & 2 & 10.3 & 30 & 300 & 1.0 & 16.0 \\
\hline
\end{tabular}

Hasil dari kebutuhan air irigasi memiliki nilai yang beragam akan tetapi untuk nilai kebutuhan air disawah yang paling besar terdapat di kebutuhan air untuk penyiapan lahan yaitu pada bulan November periode 2 sebesar $0,42 \mathrm{~m}^{3} / \mathrm{dt}$. Nilai kebutuhan air irigasi terbesar ini yang nantinya akan debit kebutuhan air dengan mengalikan luas petak nya yaitu sebesar 50 ha. Sehingga untuk debit kebutuhan air didapatkan sebesar 0,1 $\mathrm{m}^{3} / \mathrm{dt}$ untuk memenuhi air luas petak sebesar 50 ha. Maka dari itu didapatkan bukaan pintu air sebesar 0,27 $\mathrm{m}$ dengan aliran bebas. Tabel kebutuhan air irigasi disajikan pada Tabel 7. 
JSIL | Sulaecha dan Setiawan : Desain Pintu Air Berbantu Kamputer untuk Saluran Irigasi Tersier di Daerah Irigasi

Cikarawang Bogor

Tabel 7 Hasil Kebutuhan Air Irigasi

\begin{tabular}{|c|c|c|c|c|c|c|c|c|c|c|c|c|c|c|c|}
\hline \multirow{3}{*}{$\begin{array}{l}\mathrm{M} \\
\mathrm{T}\end{array}$} & \multirow{3}{*}{ Bulan } & \multirow{3}{*}{$\begin{array}{l}\mathrm{P} \\
\mathrm{e} \\
\mathrm{r}\end{array}$} & \multirow{3}{*}{ Hari } & \multirow{3}{*}{ ETo } & \multirow{3}{*}{\multicolumn{2}{|c|}{ P WLR }} & \multirow{3}{*}{$\operatorname{Re}$} & \multicolumn{8}{|c|}{ Padi } \\
\hline & & & & & & & & \multicolumn{3}{|c|}{$\begin{array}{l}\text { Koefisien } \\
\text { Tanaman }\end{array}$} & \multirow[t]{2}{*}{ ETc } & \multirow{2}{*}{\multicolumn{2}{|c|}{$\begin{array}{l}\text { NFR IR } \\
\mathrm{nm} / \text { hari) }\end{array}$}} & \multicolumn{2}{|c|}{ DR } \\
\hline & & & & & & & & $\mathrm{c} 1$ & $\mathrm{c} 2$ & $\mathrm{c}$ & & & & $(\mathrm{lt} / \mathrm{dt} / \mathrm{Ha})$ & $(\mathrm{m} 3 / \mathrm{dt})$ \\
\hline \multirow{8}{*}{ I } & \multirow{2}{*}{ NOP } & 1 & 15 & \multirow{2}{*}{4.8} & \multirow[b]{2}{*}{2} & 0 & 4.4 & LP & & LP & 16.2 & 13.8 & 17.2 & 1.99 & 0.39 \\
\hline & & 2 & 15 & & & 0 & 3.1 & 1.1 & LP & LP & 16.2 & 15.1 & 18.9 & 2.18 & 0.42 \\
\hline & \multirow{2}{*}{ DES } & 1 & 15 & \multirow{2}{*}{4.7} & \multirow[b]{2}{*}{2} & 0 & 7.5 & 1.1 & 1.1 & 1.1 & 5.2 & -0.3 & -0.4 & -0.05 & -0.01 \\
\hline & & 2 & 16 & & & 1.1 & 3.1 & 1.1 & 1.1 & 1.1 & 5.1 & 5.1 & 6.3 & 0.73 & 0.14 \\
\hline & \multirow{2}{*}{ JAN } & 1 & 15 & \multirow{2}{*}{4.5} & \multirow{2}{*}{2} & 1.1 & 3.7 & 1.1 & 1.1 & 1.1 & 4.7 & 4.1 & 5.1 & 0.59 & 0.11 \\
\hline & & 2 & 16 & & & 2.2 & 2.9 & 0.9 & 1.1 & 1.0 & 4.4 & 5.6 & 7.0 & 0.81 & 0.16 \\
\hline & \multirow{2}{*}{ FEB } & 1 & 14 & \multirow{2}{*}{4.9} & \multirow{2}{*}{2} & 1.1 & 5.5 & 0.0 & 0.9 & 0.5 & 2.2 & -0.1 & -0.1 & -0.02 & 0.00 \\
\hline & & 2 & 14 & & & 1.1 & 4.6 & & 0.0 & 0.0 & 0.0 & -1.5 & -1.9 & -0.22 & -0.04 \\
\hline \multirow{8}{*}{ II } & \multirow{2}{*}{ MAR } & 1 & 15 & \multirow{2}{*}{4.6} & $?$ & 0 & 5.2 & LP & & LP & 15.9 & 12.7 & 15.9 & 1.84 & 0.36 \\
\hline & & 2 & 16 & & 2 & 0 & 4.2 & 1.1 & LP & LP & 15.9 & 13.7 & 17.2 & 1.99 & 0.39 \\
\hline & & 1 & 15 & & & 0 & 3.3 & 1.1 & 1.1 & 1.1 & 4.9 & 3.6 & 4.5 & 0.52 & 0.10 \\
\hline & APR & 2 & 15 & 4.4 & 2 & 0 & 1.6 & 1.1 & 1.1 & 1.1 & 4.8 & 5.2 & 6.5 & 0.75 & 0.15 \\
\hline & MEI & 1 & 15 & 30 & 2 & 0 & 2.5 & 1.1 & 1.1 & 1.1 & 4.1 & 3.7 & 4.6 & 0.53 & 0.10 \\
\hline & MILT & 2 & 16 & 5.9 & 2 & 0 & 0.1 & 0.9 & 1.1 & 1.0 & 3.8 & 5.8 & 7.2 & 0.84 & 0.16 \\
\hline & JUN & 1 & 15 & 37 & 2 & 1.1 & 1.0 & 0.0 & 0.9 & 0.5 & 1.7 & 3.8 & 4.7 & 0.54 & 0.11 \\
\hline & & 2 & 15 & & & 1.1 & 0.2 & & 0.0 & 0.0 & 0.0 & 2.9 & 3.6 & 0.42 & 0.08 \\
\hline & & 1 & 15 & & & 2.2 & 0.3 & 0.5 & & 0.5 & 2.0 & 5.9 & 7.3 & 0.85 & 0.17 \\
\hline & JUL & 2 & 16 & 3.9 & 2 & 1.1 & 2.0 & 0.6 & 0.5 & 0.5 & 2.1 & 3.3 & 4.1 & 0.47 & 0.09 \\
\hline & $\Delta$ & 1 & 15 & 11 & $?$ & 1.1 & 1.9 & 1.0 & 0.6 & 0.8 & 3.2 & 4.4 & 5.5 & 0.63 & 0.12 \\
\hline III & $\mathrm{AUI}$ & 2 & 16 & 4.1 & 2 & 0 & 6.8 & 1.0 & 1.0 & 1.0 & 4.0 & -0.8 & -1.1 & -0.12 & -0.02 \\
\hline & SED & 1 & 15 & 45 & 7 & 0 & 5.2 & 1.1 & 1.0 & 1.0 & 4.5 & 1.3 & 1.7 & 0.19 & 0.04 \\
\hline & $\mathrm{SEF}$ & 2 & 15 & 4.5 & 2 & 0 & 8.4 & 1.0 & 1.1 & 1.0 & 4.6 & -1.8 & -2.2 & -0.26 & -0.05 \\
\hline & OKT & 1 & 15 & 5.0 & 2 & 0 & 4.3 & 1.0 & 1.0 & 1.0 & 4.9 & 2.6 & 3.3 & 0.38 & 0.07 \\
\hline & & 2 & 16 & 5.0 & 2 & 0 & 2.7 & 0.0 & 1.0 & 0.5 & 2.4 & 1.7 & 2.1 & 0.24 & 0.05 \\
\hline
\end{tabular}

Perhitungan debit aliran dari pintu dianalisa menggunakan metode Swamee (1992). Untuk mendapatkan nilai koefisien pengaliran $\left(\mathrm{C}_{\mathrm{d}}\right)$ dan bukaan pintu air maka digunakan fasilitas SOLVER yang terdapat dalam Ms. Excel. Untuk nilai $\mathrm{C}_{\mathrm{d}}$ yang didapatkan sebesar 0,5. Dalam hal ini menurut Swamee (1992), $C_{d}$ yang didapatkan akan memiliki $\mathrm{C}_{d}$ maksimum yang konstan sebesar 0,611. Sehingga dalam penelitian ini memiliki nilai yang hampir mendekati. Sedangkan untuk bukaan pintu air sebesar $0,27 \mathrm{~m}$, bukaan pintu ini bisa dapat digunakan untuk mengatasi kebutuhan air irigasi tertinggi yaitu pada bulan November. Jika pada bulan-bulan yang tidak membutuhkan air irigasi lebih kecil bisa menggunakan bukaan pintu air yang lebih kecil dari nilai tersebut.

\section{Penentuan Jenis Pintu Air}

Jenis pintu yang digunakan merupakan pintu sorong. Digunakannya pintu sorong dikarenakan saluran yang dipakai merupakan saluran tersier yang memiliki debit yang lebih rendah dibandingkan dengan saluran sekunder maupun primer. Bahan pintu air sorong yang akan digunakan merupakan bahan fiberglass. Fiberglass adalah bahan campuran beberapa bahan kimia (bahan komposit) yang bereaksi dan mengeras dalam waktu tertentu. Bahan ini mempunyai beberapa keuntungan dibandingkan bahan lainya yaitu: ringan, mudah dibentuk, memiliki kekuatan yang tinggi, memiliki stabilitas dimensi yang baik, tahan terhadap panas, dingin, 
lembab, dan korosi, serta sebagai bahan insulasi listrik yang baik dan murah (Smith dan Jayad 2006).

Pada perhitungan untuk pembuatan pintu air didapatkan hasil dimensinya yaitu panjang daun pintu sebesar $0.75 \mathrm{~m}$, lebar pintu air sebesar $0.5 \mathrm{~m}$, tebal daun pintu sebesar 0.012 $\mathrm{mm}$, dikarenakan bahan yang digunakan merupakan fiberglass maka dari itu ada berupa tonjolan pintu untuk meningkatkan koofisien kontraksi berupa setengah lingkaran dengan radius sebesar $0,1 \mathrm{~m}$ dan panjang $0,49 \mathrm{~m}$. Hasil tersebut termasuk dalam standar untuk pembuatan pintu sorong menurut KemenPU (2013) yaitu dengan standar lebar 0,4 sampai $0,6 \mathrm{~m}$ dengan tinggi $<0,8 \mathrm{~m}$.

Tabel 8 Plotting Berbantu Komputer

\begin{tabular}{lclll}
\hline \multicolumn{2}{l}{ PLOTTING BERBANTU KOMPUTER } & & & \\
\hline Lebar Pintu Air (b) & $=$ & 0.5 & $\mathrm{~m}$ & \\
Tinggi Daun Pintu Air (A) & $=$ & 0.75 & $\mathrm{~m}$ & \\
Bukaan Pintu Air (a) & $=$ & 0.27 & $\mathrm{~m}$ & \\
Tebal Daun Pintu Air & $=$ & 0.012 & $\mathrm{~m}$ ISI \\
Tinggi Rangka Pintu Air (H) & $=$ & 1.2 & $\mathrm{~m}$ DISINI \\
Tonjolan Pintu & & & & \\
a. radius & $=$ & 0.10 & $\mathrm{~m}$ \\
b. panjang & $=$ & 0.49 & $\mathrm{~m}$ & \\
\hline
\end{tabular}

Berdasarkan hasil dimensi yang didapatkan nantinya akan dibuatkan scripe file atau scr untuk memudahkan mengimpor di AutoCAD agar tidak menggambar seperti biasa atau manual lagi. Tabel 8 merupakan plotting berbantu komputer yang sudah didesain sedemikian rupa. Pada Tabel 8 tersebut cukup diisi yang berwarna saja. Pada Tabel 9 Dan Tabel 10 merupakan Hasil koordinat yang sudah dimasukan ke dalam tabel ploting berbantu komputer. Hasil dari koordinat tersebut lalu bisa dijadikan script file (SCR) yang nantinya akan di import ke dala AutoCAD dan akan menghasilkan gambar tampak depan seperti gambar yang disajikan pada Gambar 3 dan gambar tampak samping yang disajikan pada Gambar 4. Serta gambar 3 Dimensi disajikan pada Gambar 5. 
JSIL | Sulaecha dan Setiawan : Desain Pintu Air Berbantu Kamputer untuk Saluran Irigasi Tersier di Daerah Irigasi Cikarawang Bogar

Tabel 9 Hasil Plotting Data Tampak Depan

\begin{tabular}{|c|c|c|c|c|}
\hline \multicolumn{5}{|c|}{ Tampak Depan } \\
\hline \multicolumn{5}{|l|}{ Pintu } \\
\hline Point & $\mathrm{X}$ & Y & $X, Y$ & Line \\
\hline 0 & 0.00 & 0.00 & 0,0 & 0,0 \\
\hline 1 & 0.50 & 0.00 & $0.5,0$ & $0.5,0$ \\
\hline 2 & 0.50 & 0.75 & $0.5,0.75$ & $0.5,0.75$ \\
\hline 3 & 0.00 & 0.75 & $0,0.75$ & $0,0.75$ \\
\hline 4 & 0.00 & 0.00 & 0,0 & close \\
\hline \multicolumn{5}{|c|}{ Tonjolan } \\
\hline Point & $\mathrm{X}$ & Y & $\mathrm{X}, \mathrm{Y}$ & Line \\
\hline 0 & 0.005 & 0.000 & $0.005,0$ & $0.005,0$ \\
\hline 1 & 0.495 & 0.000 & $0.495,0$ & $0.495,0$ \\
\hline 2 & 0.495 & 0.100 & $0.495,0.1$ & $0.495,0.1$ \\
\hline 3 & 0.005 & 0.100 & $0.005,0.1$ & $0.005,0.1$ \\
\hline 4 & 0.005 & 0.000 & $0.005,0$ & close \\
\hline \multicolumn{5}{|c|}{ Lubang Handle } \\
\hline Point & $\mathrm{X}$ & Y & $\mathrm{X}, \mathrm{Y}$ & Line \\
\hline 0 & 0.175 & 0.650 & $0.175,0.65$ & $0.175,0.65$ \\
\hline 1 & 0.325 & 0.650 & $0.325,0.65$ & $0.325,0.65$ \\
\hline 2 & 0.325 & 0.700 & $0.325,0.7$ & $0.325,0.7$ \\
\hline 3 & 0.175 & 0.700 & $0.175,0.7$ & $0.175,0.7$ \\
\hline 4 & 0.175 & 0.650 & $0.175,0.65$ & close \\
\hline \multicolumn{5}{|l|}{ Logo } \\
\hline Point & $\mathrm{X}$ & Y & $X, Y$ & Line \\
\hline 0 & 0.150 & 0.300 & $0.15,0.3$ & $0.15,0.3$ \\
\hline 1 & 0.350 & 0.300 & $0.35,0.3$ & $0.35,0.3$ \\
\hline 2 & 0.350 & 0.500 & $0.35,0.5$ & $0.35,0.5$ \\
\hline 3 & 0.150 & 0.500 & $0.15,0.5$ & $0.15,0.5$ \\
\hline 4 & 0.150 & 0.300 & $0.15,0.3$ & close \\
\hline
\end{tabular}

Tabel 10 Hasil Plotting Data Tampak Samping

Plotting Data Tampak Samping

\begin{tabular}{|c|c|c|c|c|}
\hline \multicolumn{5}{|l|}{ Pintu } \\
\hline point & $X$ & $\mathrm{Y}$ & $\mathrm{X}, \mathrm{Y}$ & Line \\
\hline 0 & 0.00 & 0.00 & 0,0 & 0,0 \\
\hline 1 & 0.01 & 0.00 & $0.012,0$ & $0.012,0$ \\
\hline 2 & 0.01 & 0.75 & $0.012,0.75$ & $0.012,0.75$ \\
\hline 3 & 0.00 & 0.75 & $0,0.75$ & $0,0.75$ \\
\hline 4 & 0.00 & 0.00 & 0,0 & Close \\
\hline \multicolumn{5}{|c|}{ garis kotak bayangan } \\
\hline point & $\mathrm{X}$ & $\mathrm{Y}$ & $\mathrm{X}, \mathrm{Y}$ & Line \\
\hline 0 & 0.012 & 0 & $0.012,0$ & $0.012,0$ \\
\hline 1 & 0.022 & 0 & $0.022,0$ & $0.022,0$ \\
\hline 2 & 0.022 & 0.2 & $0.022,0.2$ & $0.022,0.2$ \\
\hline 3 & 0.012 & 0.2 & $0.012,0.2$ & $0.012,0.2$ \\
\hline 4 & 0 & 0 & 0,0 & close \\
\hline \multicolumn{5}{|c|}{ Tonjolan } \\
\hline 0 & 0.012 & 0.2 & $0.012,0.2$ & $0.012,0.2$ \\
\hline 1 & 0.022 & 0.1 & $0.022,0.1$ & $0.22,0.1$ \\
\hline 2 & 0.012 & 0 & $0.012,0$ & $0.012,0$ \\
\hline 3 & 0 & 0 & 0,0 & close \\
\hline \multicolumn{5}{|c|}{ hapus garis kotak bayangan } \\
\hline point & $\mathrm{X}$ & $\mathrm{Y}$ & $\mathrm{X}, \mathrm{Y}$ & Erase \\
\hline 0 & 0.012 & 0 & $0.012,0$ & $0.012,0$ \\
\hline 1 & 0.022 & 0 & $0.022,0$ & $0.022,0$ \\
\hline 2 & 0.022 & 0.2 & $0.022,0.2$ & $0.022,0.2$ \\
\hline 3 & 0.012 & 0.2 & $0.012,0.2$ & $0.012,0.2$ \\
\hline 4 & 0 & 0 & 0,0 & close \\
\hline
\end{tabular}




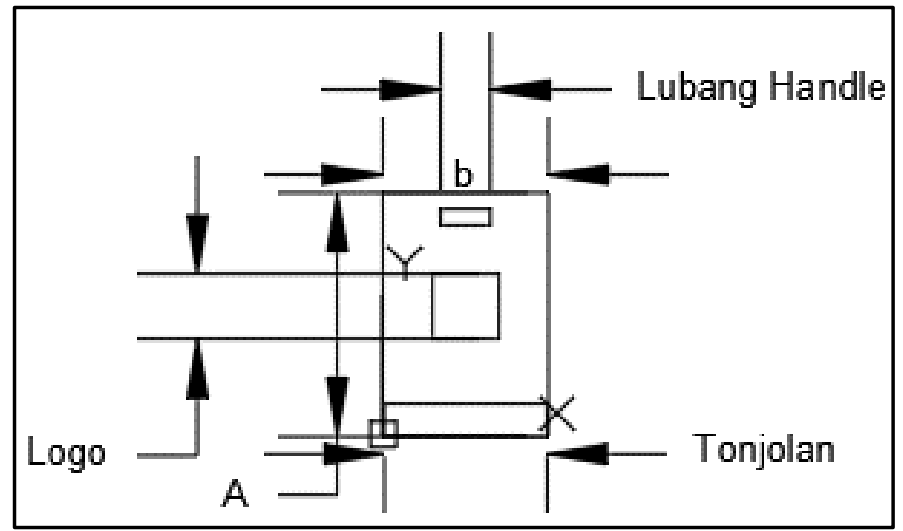

Gambar 3 Tampak Depan Pintu Air

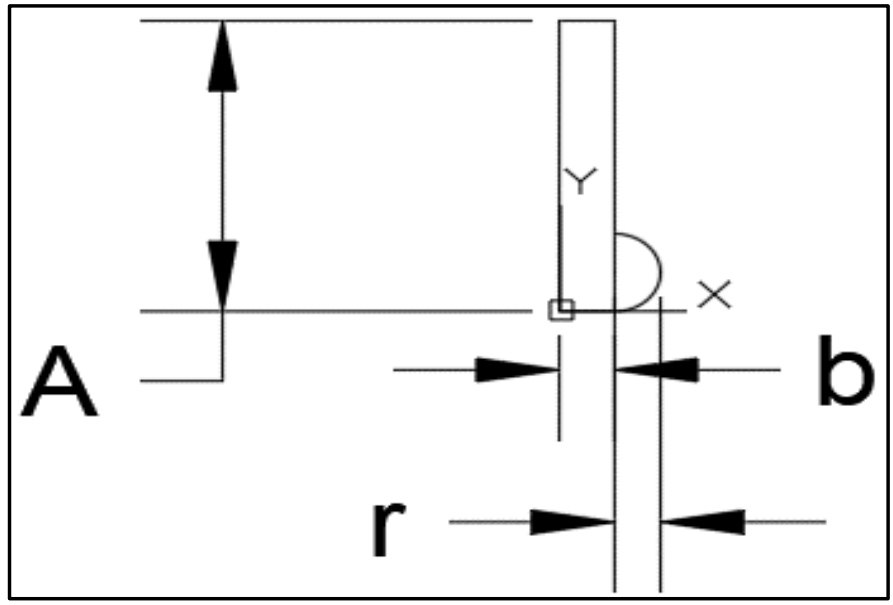

Gambar 4 Tampak Samping Pintu Air

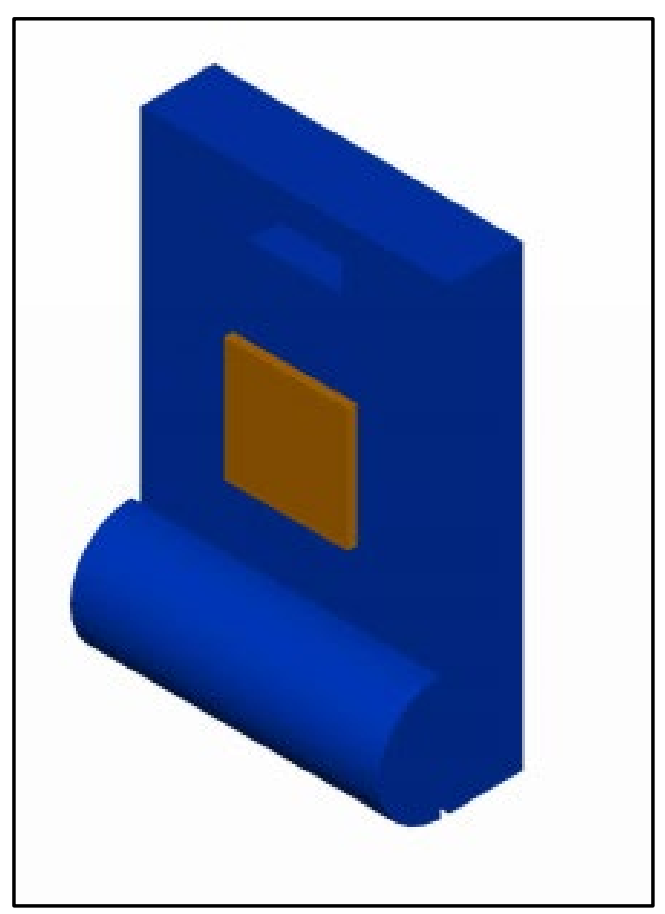

Gambar 53 Dimensi 
JSIL | Sulaecha dan Setiawan : Desain Pintu Air Berbantu Kamputer untuk Saluran Irigasi Tersier di Daerah Irigasi Cikarawang Bogor

Tabel 11 Rencana Anggaran Biaya

\begin{tabular}{|c|c|c|c|c|c|}
\hline No & Uraian & Satuan & Volume & Harga Satuan & Jumlah \\
\hline \multicolumn{6}{|c|}{ Bahan } \\
\hline 1 & Komposisi Polymer & $\mathrm{kg}$ & 2.034 & 69000 & 140346 \\
\hline 2 & Chopped Stand Mat & $\mathrm{kg}$ & 0.261 & 40000 & 10440 \\
\hline 3 & Woven Roving & $\mathrm{kg}$ & 0.784 & 45000 & 35280 \\
\hline 4 & Mirror Glaze & $\mathrm{kg}$ & 0.125 & 180000 & 22500 \\
\hline 5 & PPA & $\mathrm{kg}$ & 0.125 & 80000 & 10000 \\
\hline 6 & Papan Multipleks & lembar & 1 & 140000 & 140000 \\
\hline 7 & Kayu Reng & batang & 0.125 & 15000 & 1875 \\
\hline 8 & Paku triplek & $\mathrm{kg}$ & 0.125 & 15000 & 1875 \\
\hline 9 & Dempul & $\mathrm{kg}$ & 0.01 & 50000 & 500 \\
\hline \multicolumn{6}{|c|}{ Biaya Tukang } \\
\hline 1 & Tukang Kayu (Cetakan) & orang/hari & 1 & 100000 & 100000 \\
\hline 2 & Tukang Fiberglass & orang/hari & 2 & 150000 & 300000 \\
\hline 3 & Finishing & orang/hari & 1 & 75000 & 75000 \\
\hline \multicolumn{5}{|c|}{ Total Biaya Pembuatan Pintu Fiberglass (GFRP) } & 837816 \\
\hline
\end{tabular}

Tabel 11 menunjukan besarnya biaya pembuatan daun pintu berbahan fiberglass yaitu sebesar Rp. 837.816 atau jika dibulatkan menjadi Rp.838.000,sedangkan untuk pintu sorong baja membutuhkan biaya sebesar Rp.7.500.000,-. Biaya pembuatan daun pintu berbahan Fiberglass memiliki dimensi $0,75 \times 0,5 \times 0.012 \mathrm{~m}$ dan baja memiliki dimensi $0.7 \times 0.5 \mathrm{~m}$. Oleh karena itu biaya yang dikeluarkan untuk membuat daun pintu berbahan fiberglass lebih murah dibandingkan dengan daun pintu berbahan baja. Berdasarkan kedua tabel tersebut dapat dikatakan untuk harga lebih ekonomis pintu dengan menggunakan fiberglass dibandingkan dengan menggunakan baja.

Tabel 11 memiliki komponen terbesar dalam pembuatan daun pintu berbahan fiberglass adalah komposisi polymer yaitu sebesar Rp.140.346,- hal ini sejalan dengan Tusi (2010), yang menyatakan jika biaya tebesar pembuatan pintu air berbahan fiberglass yaitu komposisi polymer dan untuk komponen polymer akan semakin besar biayanya apabila tebal dan dimensi luasan pintu semakin besar.

\section{KESIMPULAN}

Berdasarkan hasil penelitian ini, maka kesimpulan yang diperoleh adalah sebagai berikut :

1. Diperoleh curah hujan efektif yaitu sebesar 1806,3 mm.

2. Evapotranspirasi tertinggi sebesar 5,5 $\mathrm{mm} / \mathrm{hari}$ dan evapotranspirasi tanaman terendah sebesar $4 \mathrm{~mm} /$ hari.

3. Kebutuhan air irigasi tertinggi didapatkan sebesar sebesar 2,18 $1 \mathrm{t} / \mathrm{dt} / \mathrm{ha}$ atau $0,42 \mathrm{~m}^{3} / \mathrm{dt}$.

4. Rancangan desain pintu air dengan menggunakan plotting data berupa script file (SCR). Dimensi yang didapatkan lebar $0,5 \mathrm{~m}$, panjang daun pintu 0,75 $\mathrm{m}$, tebal $0,012 \mathrm{~m}$, serta bukaan pintu air $0,27 \mathrm{~m}$. Bukaan pintu air ini digunakan pada saat bulan November pada periode II. Jika terjadi perubahan maka faktor yang diubah di debit kebutuhan air tanaman untuk menentukan bukaan pintu.

5. Biaya pembuatan daun pintu yang dibutuhkan untuk pintu berbahan fiberglass yaitu sebesar Rp. 837.816 atau jika dibulatkan menjadi Rp.838.000,- sedangkan 


$$
\begin{aligned}
& \text { untuk pintu sorong baja } \\
& \text { membutuhkan biaya sebesar } \\
& \text { Rp.3.500.000,- . }
\end{aligned}
$$

\section{DAFTAR PUSTAKA}

Apriyanto H. 2015. Rancangan bangun pintu air otomatis menggunakan water level float switch berbasis mikrokontroler. Jurnal SISFOKOM. 4 (1) : 22-27.

Folkes E L, Edwin P H, Kusa B N. 2017. Pengembangan pintu air irigasi pintar berbasis arduino untuk daerah Irigasi Manikin. Jurnal Rekayasa Elektrikal. 13(3) : 139144.

[KemenPU] Kementrian Pekerjaan Umum. 2013. Kriteria Perencanaan Bagian Perencanaan Jaringan Irigasi KP01. Jakarta (ID): Direktorat Jendral Sumber Daya Air Direktorat Irigasi dan Rawa.

Smith WF, Jayad. 2006. Foundations of Materials Science and Engineering (4th ed). New York (NY) : McGraw-Hill.

Swamee P K. 1992. Sluice-Gate Discharge Equation. Journal of Irrigation and Drainage Engineering. 118(1) : 56-60.

Taolin RICO. 2014. Pendugaan evapotranspirasi padi sawah menggunakan Metode Nisbah Bowen (studi kasus di Kabupaten Indramayu). [Tesis]. Bogor (ID) : Institut Pertanian Bogor.

Tusi A. 2010. Rancangan bangun otomatisasi irigasi (desain pintu air dan simulasi system kendali level muka air sawah). [Tesis]. Bogor (ID) : Institut Pertanian Bogor. 
JSIL | Sulaecha dan Setiawan : Desain Pintu Air Berbantu Kamputer untuk Saluran Irigasi Tersier di Daerah Irigasi Cikarawang Bogor 